\title{
Sodium phenylbutyrate antagonizes prostate cancer through the induction of apoptosis and attenuation of cell viability and migration
}

This article was published in the following Dove Press journal:

OncoTargets and Therapy

12 May 2016

Number of times this article has been viewed

\section{Yawen $\mathrm{Xu}^{*}$ \\ Shaobo Zheng* \\ Binshen Chen \\ Yong Wen \\ Shanwen Zhu}

Department of Urology, Zhujiang Hospital, Southern Medical University, Guangzhou, People's Republic of China

*These authors contributed equally to this work
Correspondence: Yawen Xu;

Shaobo Zheng

Department of Urology, Zhujiang Hospital, Southern Medical University,

No 253 Industrial Avenue, Guangzhou 510282, People's Republic of China

Tel/fax +86206278 2725

Email mouse72@foxmail.com;

IhIhIh864@sina.com
Background: Prostate cancer ( $\mathrm{PCa}$ ) is a leading cause of cancer-related death in men. Sodium phenylbutyrate (SPB) has shown its potential as an anticancer therapy in numerous cancer types. In the present study, we attempted to assess the effect of SPB against PCa and whether this treatment was associated with the regulation of survivin.

Methods: Two human PCa cancer cell lines, DU145 and PC3, were used in the present study. Cell Counting Kit-8 (CCK-8) assay was conducted to measure the proliferation of PCa cells incubated with SPB. The effect of SPB on the cell apoptosis, cell colony formation ability, and cell morphological change was also assessed. Transwell experiment and Western blotting assay were performed to determine the effect of SPB on the migration and invasion ability of both cell types. Moreover, the expression pattern of survivin and MAPK members in both cell types after the treatment of SPB was also detected. Additionally, an in vivo tumor formation assay was performed to evaluate the treatment potential of SPB against PCa.

Results: We found that the viability of PCa cells was significantly inhibited by SPB treatment. As illustrated by flow cytometry, for DU145 cell line the average apoptotic rate of SPB-treated cells was significantly lower than that of the control group $(P<0.05)$; similar results were also seen for PC3 $(P<0.05)$. SPB administration also attenuated the colony formation and migration abilities in both cell lines. The expression level of survivin in SPB-treated cells was significantly downregulated, while the phosphorylation of p-38 and ERK was enhanced. Furthermore, in vivo tumor formation of both cell lines was suppressed by SPB as well.

Conclusion: The above results confirmed the potential of SPB as an effective therapeutic agent for the prevention or treatment of PCa. This amelioration might be due to the blockade of the survivin pathway.

Keywords: apoptosis, prostate cancer, sodium phenylbutyrate, survivin

\section{Introduction}

Prostate cancer ( $\mathrm{PCa})$ is one of the most frequently diagnosed cancer types in men worldwide. ${ }^{1}$ Although most patients with the low-risk, localized PCa initially respond to surgical treatment well, there are still $10 \%-20 \%$ patients with poor prognosis developing castration-resistant prostate cancer. ${ }^{2}$ Worse still, the prognosis following traditional PCa treatment modalities also varies greatly: some patients may survive for 15 years without any important effect on mortality, while others may have metastasis within 2 years. ${ }^{3,4}$ Therefore, it is difficult for clinicians to provide accurate prediction of the course of this cancer.

Sodium phenylbutyrate (SPB) is a histone deacetylase inhibitor and possesses a broad spectrum of molecular functions. The compound is capable of modulating the 
structure of chromatin and contributes to the regulation of multiple cell cycle and apoptosis-related genes. ${ }^{5,6}$ Based on available reports, SPB exerts an antagonizing effect against certain types of cancer cells, which has been attributed to its capability to decrease cell proliferation, enhance cell differentiation, and induce apoptosis and cell cycle arrest. ${ }^{7}$ However, to the best of our knowledge, few studies have paid attention to the effect of SPB against PCa, not to mention the evaluation for SPB as a potential anti-PCa therapy.

It has been demonstrated that detection of tumor cells circulating in the blood stream (circulating tumor cells) has the potential to become a reliable assay for early diagnosis of various cancers. ${ }^{8}$ One of the most sensitive markers is survivin, which plays a critical role in promoting cell cycle and mediating mitosis during embryonic development. ${ }^{9}$ It has been reported that survivin is involved in the treatment effect of baicalein on bladder cancer in an MAPK pathway-dependent manner. ${ }^{10}$ Regarding its role in $\mathrm{PCa}$, the level of survivin was positively correlated with the PCa's distant metastasis in 88 PCa patients, ${ }^{11}$ representing the potential of survivin as a promising target for the development of an anti-PCa therapy. Interestingly, a previous study has revealed that SPB is capable of downregulating various anti-apoptosis genes, including survivin. ${ }^{12}$ Putting all the information together, it is reasonable to assess the potential of SPB as a novel therapy targeting survivin for the prevention or even treatment of PCa.

The main objective of this study was to investigate the impact of SPB treatment on the survival and migration of PCa cells. Furthermore, the expression patterns of survivin and members of MAPK pathway were investigated. It was expected that findings of the present study would elaborate the effect of SPB on PCa cells and preliminarily reveal the underlying mechanism involved in the treatment.

\section{Methods}

\section{Chemicals, animals, and cell cultures}

SPB was purchased from Selleck Chemicals (Houston, TX, USA) and dissolved in double-distilled (dd) $\mathrm{H}_{2} \mathrm{O}$. Antibodies against survivin, p38, phosphorylated p38 (p-p38), ERK, p-ERK, JNK, p-JNK, and GAPDH were purchased from Promega Corporation (Fitchburg, WI, USA). Eight-week-old male Sprague Dawley rats (weighing 240-260 g) were purchased from the Animal Center of Sun Yat-sen University and maintained in cages at room temperature $\left(20^{\circ} \mathrm{C}-25^{\circ} \mathrm{C}\right)$ with a constant humidity $(55 \% \pm 5 \%)$ with free access to food and water. All animal experiments were conducted in the accordance with the Institutional Animal Ethics Committee and Animal Care Guidelines for the Care and Use of Laboratory
Animals of Southern Medical University which governed the use of the animals. PCa cell lines DU145 and PC3 were obtained from American Type Culture Collection (ATCC, Manassas, VA, USA). DU145 cells were grown in Eagle's Minimum Essential Medium supplemented with $1.8 \mathrm{mM}$ $\mathrm{CaCl}_{2}$, and PC3 cells were grown in F-12 medium. Both media were supplemented with $10 \%$ fetal bovine serum and $1 \%$ penicillin/streptomycin. For experimental use, cells from three to six passages were collected. This study was approved by Zhujiang Hospital, Southern Medical University.

\section{CCK-8 assay}

The dose of SPB for experimental use was determined using CCK-8 method. Both cell types were incubated with different SPB concentrations $(0 \mathrm{mM}, 0.1 \mathrm{mM}, 0.5 \mathrm{mM}$, $1 \mathrm{mM}, 2 \mathrm{mM}, 4 \mathrm{mM}$, and $8 \mathrm{mM}$ ) to determine the half maximal inhibitory concentration $\left(\mathrm{IC}_{50}\right)$ of SPB. Briefly, $50 \mu \mathrm{L}$ of exponentially growing cells at the concentration of $2 \times 10^{5}$ cells $/ \mathrm{mL}$ was seeded into one well of a 96-well plate and cultured routinely. After incubation, CCK-8 solution $(10 \mu \mathrm{L})$ was added to each well and the cultures were incubated at $37^{\circ} \mathrm{C}$ for 90 minutes. The optical density (OD) values in different wells were recorded using a microplate reader at $450 \mathrm{~nm}$. Each concentration was represented by three replicates. $\mathrm{IC}_{50}$ was calculated using the logit model.

Based on the results of $\mathrm{IC}_{50}$ detection, the effect of SPB on the cell proliferation abilities of the two cell lines was determined using CCK- 8 assay as described above. For each cell line, cells were incubated with SPB or a vehicle of SPB for 0 hour, 24 hours, 48 hours, 72 hours, and 96 hours, and each time point was represented by three replicates.

\section{Colony formation assay and morphological change detection}

The cell lines were divided into two groups: (A) control group, in which the cells were incubated with $\mathrm{ddH}_{2} \mathrm{O}$ for 48 hours, and (B) SPB group, in which cells were incubated with $\mathrm{SPB}$ at $\mathrm{IC}_{50}$ for 48 hours. After incubation, the cells from different treatments were collected for subsequent experiments. For colony formation assay, different groups in both cell lines were suspended in $0.35 \%$ agarose (in 10\% serum media) and plated in one well of a six-well plate at a concentration of 3,000 cells/well. After 14 days in the culture, the colonies were stained with crystal violet and the number of colonies was determined. Each cell line was represented by three replicates. Moreover, the morphological changes of cells sampled from 48-hour incubation in the different groups were observed with a scanning electron microscope at $\times 1,000$ magnification. 


\section{Transwell migration assay}

For cell samples from 48 hours, a transwell experiment was conducted to measure the migration abilities: briefly, $100 \mu \mathrm{L}$ of the medium containing $1 \times 10^{5}$ cells was seeded into the upper chamber of BSA-coated $8 \mu \mathrm{M}$ pore size transwell chambers (Corning Incorporated, Corning, NY, USA). The cells were allowed to migrate through the porous membrane at $37^{\circ} \mathrm{C}$ for 4 hours. Then cells in the upper surface of the chamber were completely removed. The lower surfaces of the membranes were stained in a solution containing $1 \%$ $(\mathrm{w} / \mathrm{v})$ crystal violet in $2 \%$ ethanol for 30 seconds and then washed using $\mathrm{ddH}_{2} \mathrm{O}$. The number of cells was determined using the Image-Pro Plus 6.0 software (Nikon Corporation, Tokyo, Japan). To evaluate the invasion ability of cells under different treatments, a transwell experiment was conducted with polycarbonate membranes previously coated with $40 \mu \mathrm{L}$ matrigel $(1.5 \mathrm{mg} / \mathrm{mL}$; BD Biosciences, San Jose, CA, USA) at $37^{\circ} \mathrm{C}$ for 2 hours to form a reconstituted basement membrane.

\section{Flow cytometry}

After 48 hours of incubation, cells from different groups were incubated with $5 \mu \mathrm{L}$ Annexin $\mathrm{V}$ for 10 minutes at room temperature. Then the cells were resuspended with $1 \times$ binding buffer, and $5 \mu \mathrm{L}$ propidium iodide was added. The apoptotic rates of the two cell lines were detected with a FACScan flow cytometer (Accuri C6; BD Biosciences). The apoptotic cell rate (UR + LR-all apoptosis cell percentage) was equal to the sum of the late apoptotic (UR, upper right quadrant-advanced stage apoptosis cell percentage) and the early apoptotic rate (LR, lower right quadrant-prophase apoptosis cell percentage).

\section{Western blotting assay}

To determine the effect of SPB on the expression of survivin, p38, p-p38, ERK, p-ERK, JNK, and p-JNK, the whole protein production was extracted from different treatments of the two cell lines for Western blotting assay. GAPDH was used as reference protein. Concentration of the protein samples was determined using the bicinchoninic acid method, and $20 \mu \mathrm{g}$ of protein was subject to a $10 \%$ sodium dodecylsulfate polyacrylamide gel electrophoresis. Targeted proteins were transferred onto polyvinylidene difluoride sheets. The membranes were washed with Tris-buffered saline with Tween 20 (TBST) for 5 minutes and then transferred into the blocking buffer for incubation overnight at $4{ }^{\circ} \mathrm{C}$. After three cycles of 5 -minute washes with TBST, the primary antibody against survivin (1:1,000), p38 (1:1,000), p-p38 (1:1,000), ERK $(1: 1,000)$,
p-ERK $(1: 1,000)$, JNK $(1: 1,000)$, p-JNK $(1: 1,000)$, or GAPDH (1:1,000), all from Abcam (Cambridge, UK), was incubated with the membranes for 1 hour at room temperature. After additional three washes, secondary HRP goat anti-rabbit IgG antibodies (1:20,000; Zhongshanjinqiao, People's Republic of China) were added and incubated with the membranes for 40 minutes. After final three washes using TBST, the blots were developed using Beyo ECL Plus reagent. The images were detected and analyzed using Imaging-Pro Plus 6.0 System.

\section{Experimental tumor model}

To induce tumor formation, 30 randomly selected rats were divided into two groups (15 in each group) for PC3 and DU145 cells, respectively: (A) control group, in which Sprague Dawley (SD) rats received dorsal subcutaneous injection of $5 \times 10^{6} / 0.2 \mathrm{~mL}$ PCa cells and then rats were housed for 30 days before being gavaged with saline for 28 days, and (B) SPB group, in which SD rats received dorsal subcutaneous injection of $5 \times 10^{6} / 0.2 \mathrm{~mL}$ PCa cells and cultured for 30 days before gavaged with same volume of $2.5 \mathrm{mmol} / \mathrm{kg}$ SPB for 28 days. Every 7 days from the start of gavage, three randomly selected rats from different groups were sacrificed for the measurement of the volume of tumor. Tumor volume was calculated according to the expression of $(\pi / 6) \times a b^{2}$, in which $a$ represents the major axis of the tumor and $b$ represents the minor axis.

\section{Statistical analysis}

All the data are shown as mean \pm standard deviation. SPSS 19.0 software (IBM Corporation, Armonk, NY, USA) was used for statistical analysis. The difference between control and SPB groups was evaluated using the Student's $t$-test. $P<0.05$ was considered statistically significant.

\section{Results}

\section{SPB decreased the proliferation ability of DUI45 and PC3 cell lines}

Based on the results of $\mathrm{IC}_{50}$ detection (Table 1), SPB at a concentration of $4.989 \mathrm{mM}$ or $3.911 \mathrm{mM}$ was used for the assay

Table I Determination of $\mathrm{IC}_{50}$ of SPB for DUI45 and PC3 cell lines

\begin{tabular}{llllllll}
\hline Cell line & \multicolumn{6}{l}{$\begin{array}{l}\text { Inhibition rate (\%) under different concentrations } \\
(\mu \mathbf{M})\end{array}$} \\
\cline { 2 - 8 } & $\mathbf{0}$ & $\mathbf{0 . 1}$ & $\mathbf{0 . 5}$ & $\mathbf{I}$ & $\mathbf{2}$ & $\mathbf{4}$ & $\mathbf{8}$ \\
\hline DUI45 & 0 & 1.44 & 3.50 & 8.14 & 17.54 & $35.6 \mathrm{I}$ & $\mathbf{7 3 . 5 9}$ \\
PC3 & 0 & 10.2 & 19.56 & 20.06 & 24.74 & $33.5 \mathrm{I}$ & 81.94 \\
\hline
\end{tabular}

Abbreviations: $\mathrm{IC}_{50}$, half maximal inhibitory concentration; SPB, sodium phenylbutyrate. 
of proliferation of DU145 or PC3 cell lines, respectively. For each cell line, the $\mathrm{OD}_{450}$ values of SPB-treated cells were lower than those of normal cells since 24 hours, and the differences were statistically significant $(P<0.05)$ (Figure 1A). Moreover, there was no significant difference between the $\mathrm{OD}_{450}$ values of SPB-treated cells from different sampling time points, which showed the stable effect of SPB in inhibiting the proliferation of the PCa cell lines.

\section{Treatment with SPB attenuated the anchorage-independent growth of DUI45 and PC3 cell lines}

The capability of anchorage-independent growth of cancer cells was measured by colony formation assay. SPB treatment remarkably lowered the number of colonies for both cells, and the differences between control groups and SPB groups was statistically significant $(P<0.05)$ (Figure 1B). The decreased number of colonies represented a negative effect of SPB on the cell oncogenicity of PCa.

\section{Treatment with SPB increased the apoptosis in both cell lines and caused cell structure demolition}

Using flow cytometry, increases in the apoptotic rates of both cell lines were recorded. For DU145 cell line, the average apoptosis rate of SPB-treated cells was $37.8 \% \pm 4.5 \%$ while that of control cells was only $9.1 \% \pm 3.6 \%$; the difference was statistically significant $(P<0.05)$ (Figure $2 \mathrm{~A})$. For PC3
A

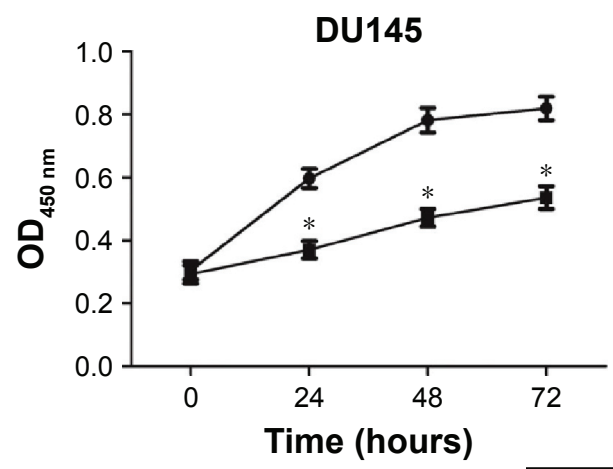

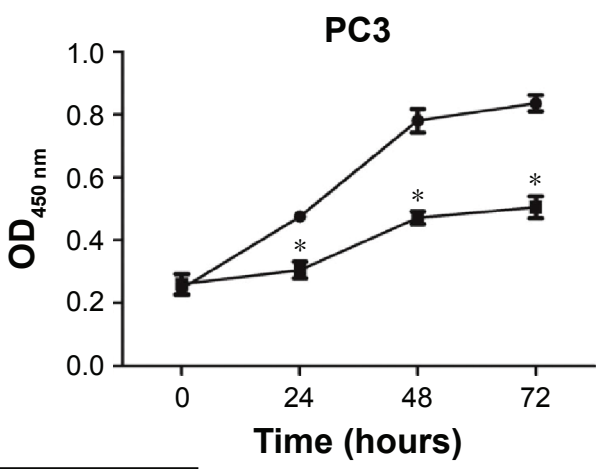

$\rightarrow$ Control $\rightarrow$ SPB
B
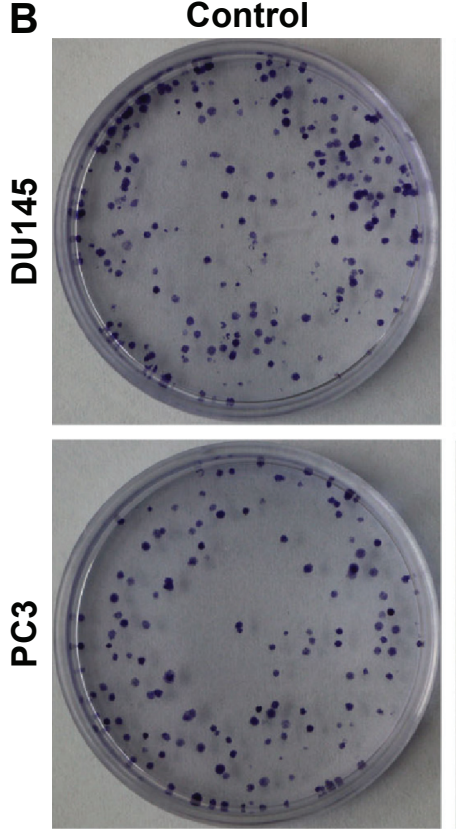

SPB
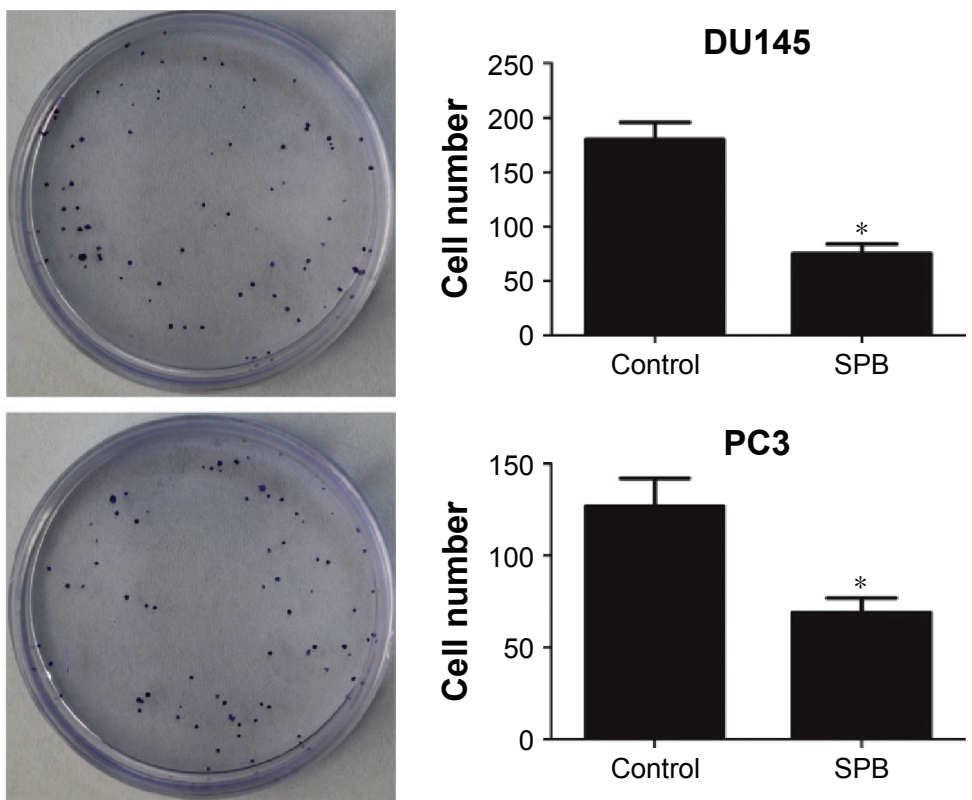

Figure I Decreased proliferation ability and anchorage-independent growth attenuation of DUI 45 and PC3 cell lines due to SPB treatment.

Notes: (A) Quantitative analysis results of CCK-8 assay, “*” means significantly different from the control group, $P<0.05$. (B) Representative images of colony formation assay. SPB treatment remarkably decreased the colony number compared to the control group.

Abbreviations: SPB, sodium phenylbutyrate; CCK-8, Cell Counting Kit-8; OD, optical density. 


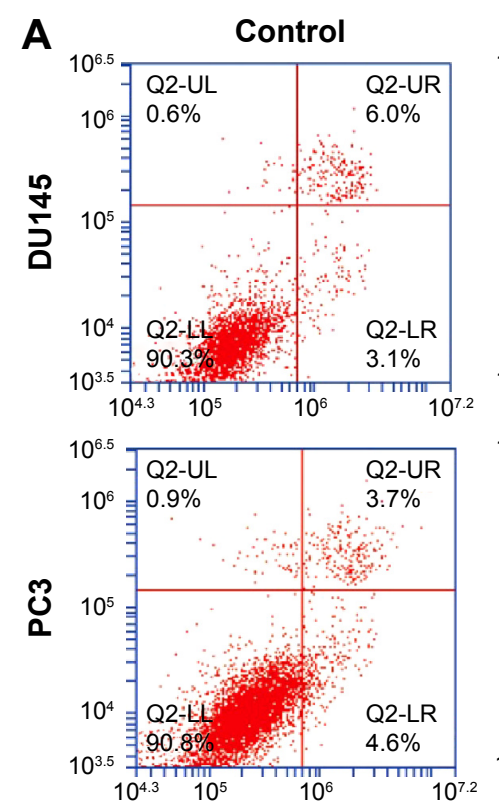

B
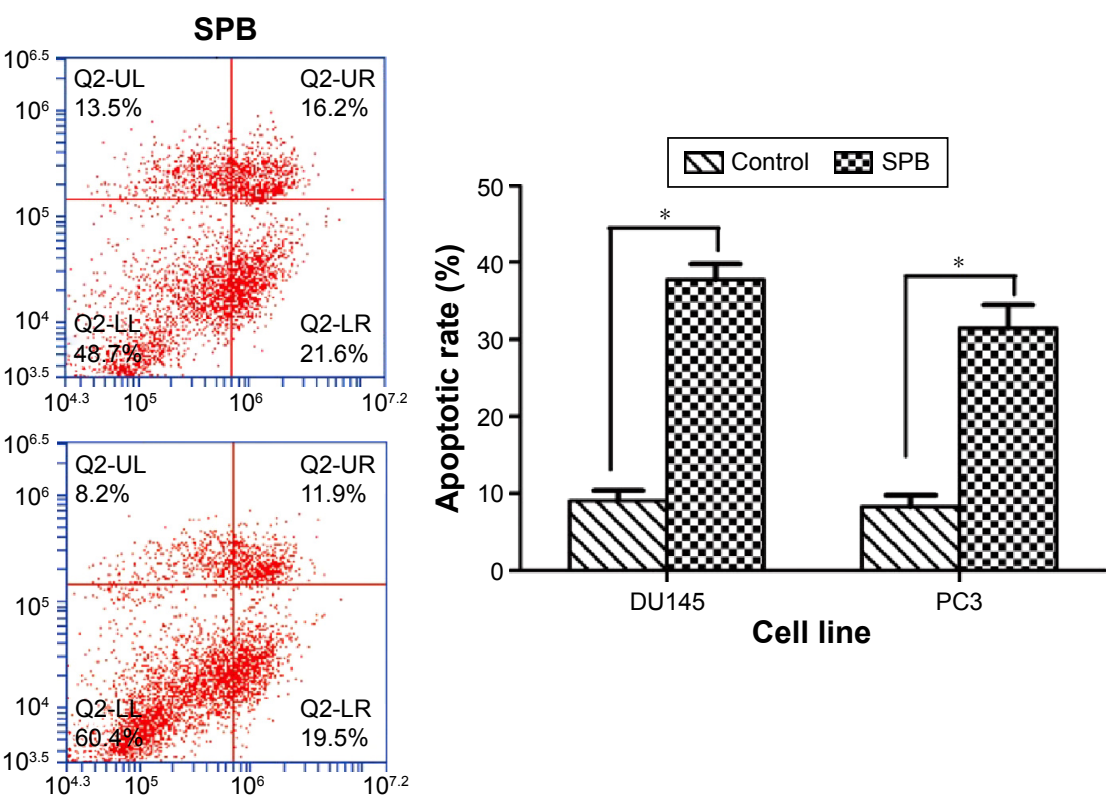

Control
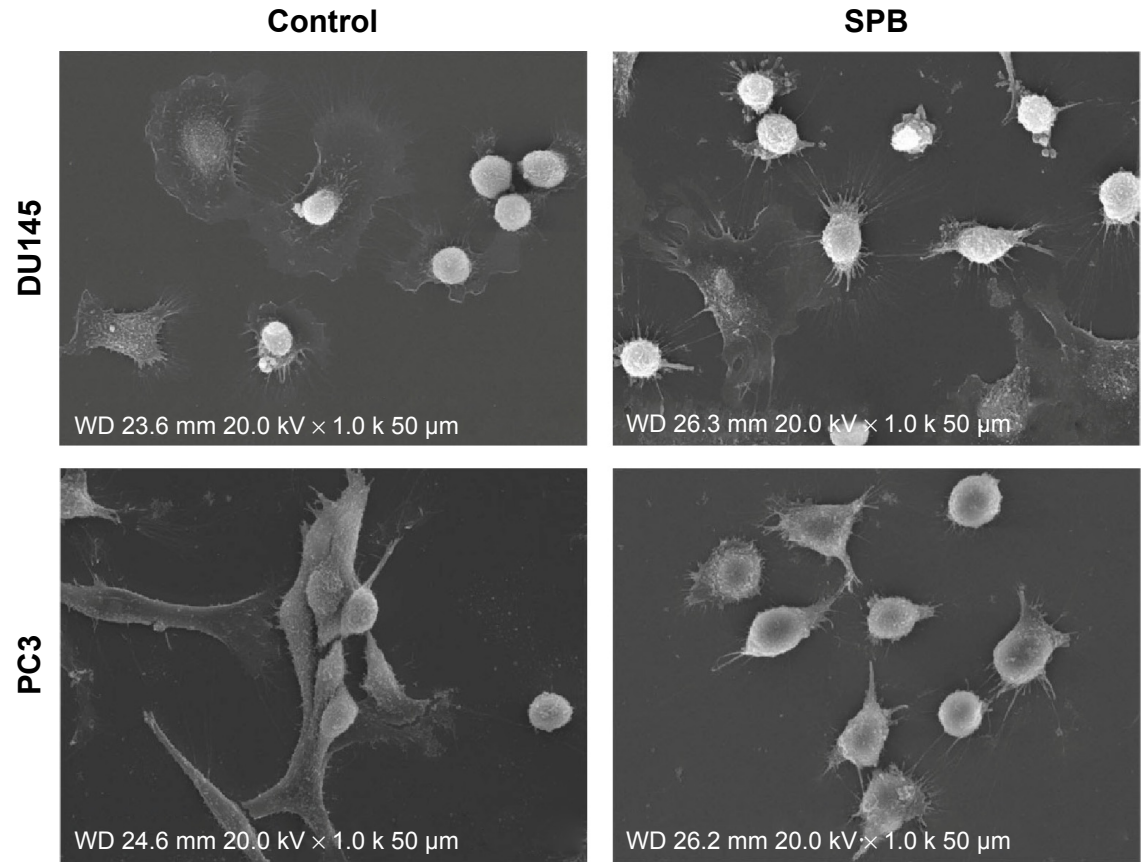

Figure 2 Induced cell apoptosis in both cell types and demolition of the cell structures of both cell lines due to SPB treatment.

Notes: (A) Representative images and quantitative analysis results of FACS, “*” means significantly different from control group, $\mathbf{P}<0.05$. (B) Representative images of scanning electric microscopy $(\times 1,000$ magnification). Cells in the SPB group expanded or shrunk dramatically due to cell membrane fracture.

Abbreviations: SPB, sodium phenylbutyrate; FACS, fluorescence-activated cell sorting.

cell line, the average apoptotic rates for SPB-treated cells and control cells were $31.4 \% \pm 8.6 \%$ and $8.3 \% \pm 2.7 \%$, respectively; the difference between control and SPB group was statistically significant $(P<0.05)$ (Figure $2 \mathrm{~B})$. Additionally, as show in Figure 2B, cells in the control group were regularly shaped, while those treated with SPB had disrupted structures to some extent: the cells expanded or shrunk dramatically as a result of membrane fracture. The results of scanning electron microscopy showed the damage due to SPB on the microstructure of PCa cells.

\section{SPB inhibited the cell migration and invasion abilities of DUI45 and PC3 cell lines}

The effect of SPB on the mobility of both cell lines was measured using a transwell experiment. Significant decrease 
in the migration and invasion ability of the SPB-treated cells was observed compared with controls (Figure 3). For DU145 cells, the cell number in the migration assay was $168 \pm 14$ for the control group and $106 \pm 7$ for the SPB group, and the difference was statistically significant $(P<0.05)$ (Figure $3 \mathrm{~A})$; the cell number in invasion assay was $156 \pm 6$ for the control group and $100 \pm 2$ for the SPB group, and the difference was, again, statistically significant $(P<0.05)$ (Figure 3B). For PC3 cells, the cell number in the migration assay was $78 \pm 12$ for the control group and $49 \pm 6$ for the SPB group, and the difference was statistically significant $(P<0.05)$ (Figure 3C); the cell number in the invasion assay was $67 \pm 4$ for the control group and $45 \pm 4$ for the SPB group, and the difference was statistically significant $(P<0.05)$ (Figure 3D).
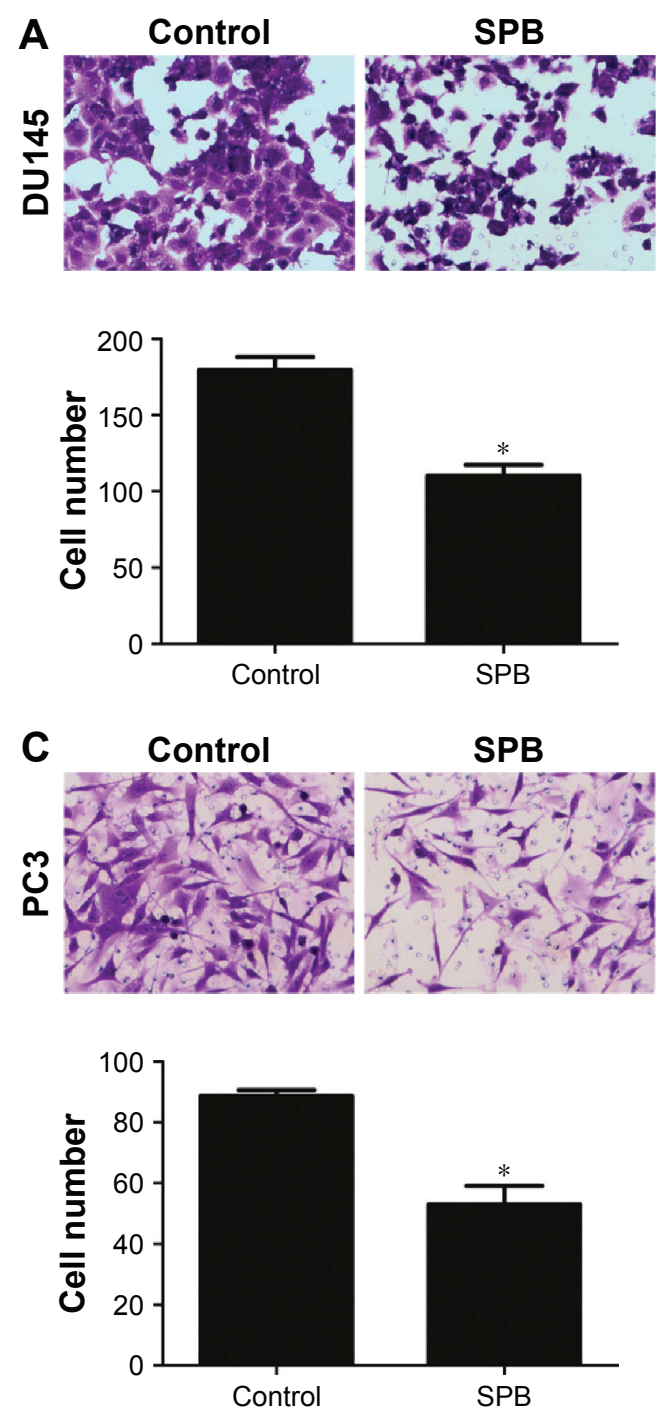

\section{Treatment with SPB inhibited the expression of survivin and activity of the MAPK pathway}

To preliminarily reveal the effect of SPB on the expression of survivin in $\mathrm{PCa}$, we conducted Western blotting assay to detect the expression change of survivin after administration of SPB. As shown in Figure 4A, the expression level of survivin in SPB-treated cells was remarkably downregulated. This was the case with both PCa cell lines. Regarding the activity of MAPK members, phosphorylation of p38 and ERK was dramatically upregulated after the administration of SPB. However, the expression of $\mathrm{p}-\mathrm{JNK}$ was not influenced by SPB treatment. The effect of SPB on apoptosis in PCa cells might be through the activation of p38 and ERK molecules (Figure 4B).
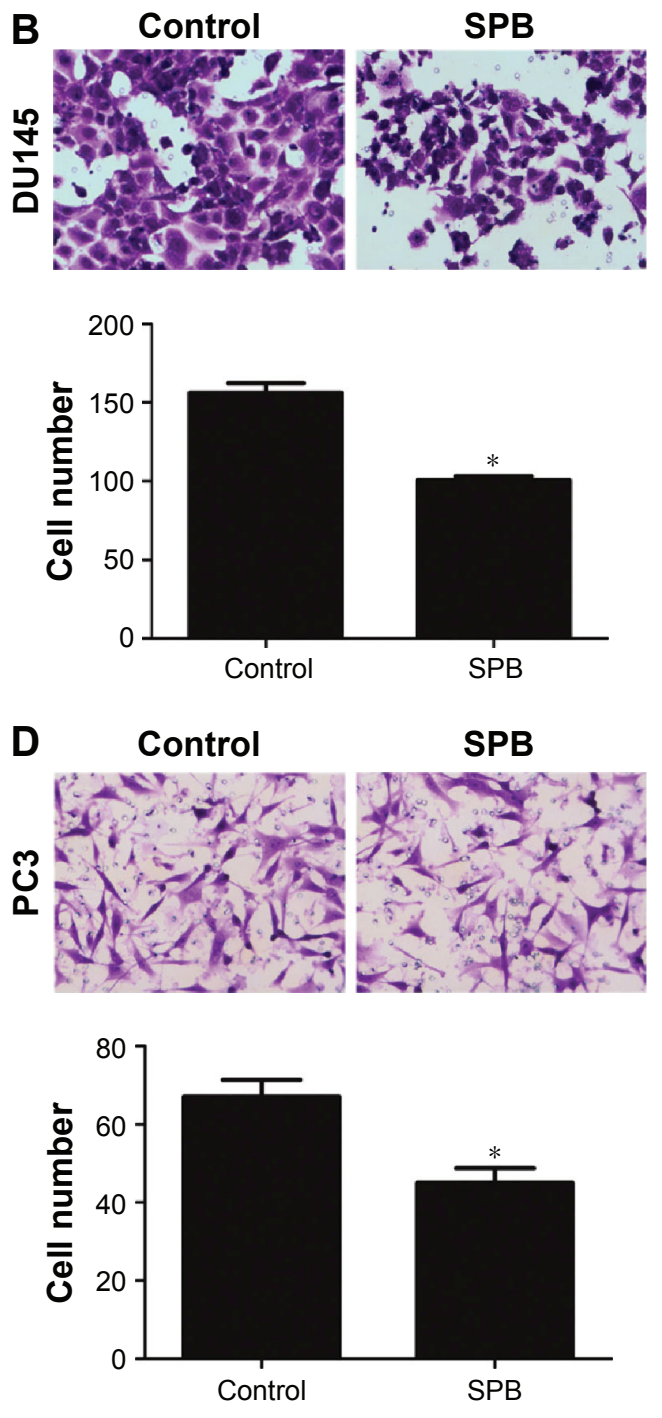

Figure 3 Representative images and quantitative analysis results of the transwell experiment.

Notes: (A) Results of migration assay for DUI45. (B) Results of invasion assay for DUI45. (C) Results of migration assay for PC3. (D) Results of invasion assay for PC3. “*” Means significantly different from control group, $P<0.05$.

Abbreviation: SPB, sodium phenylbutyrate. 


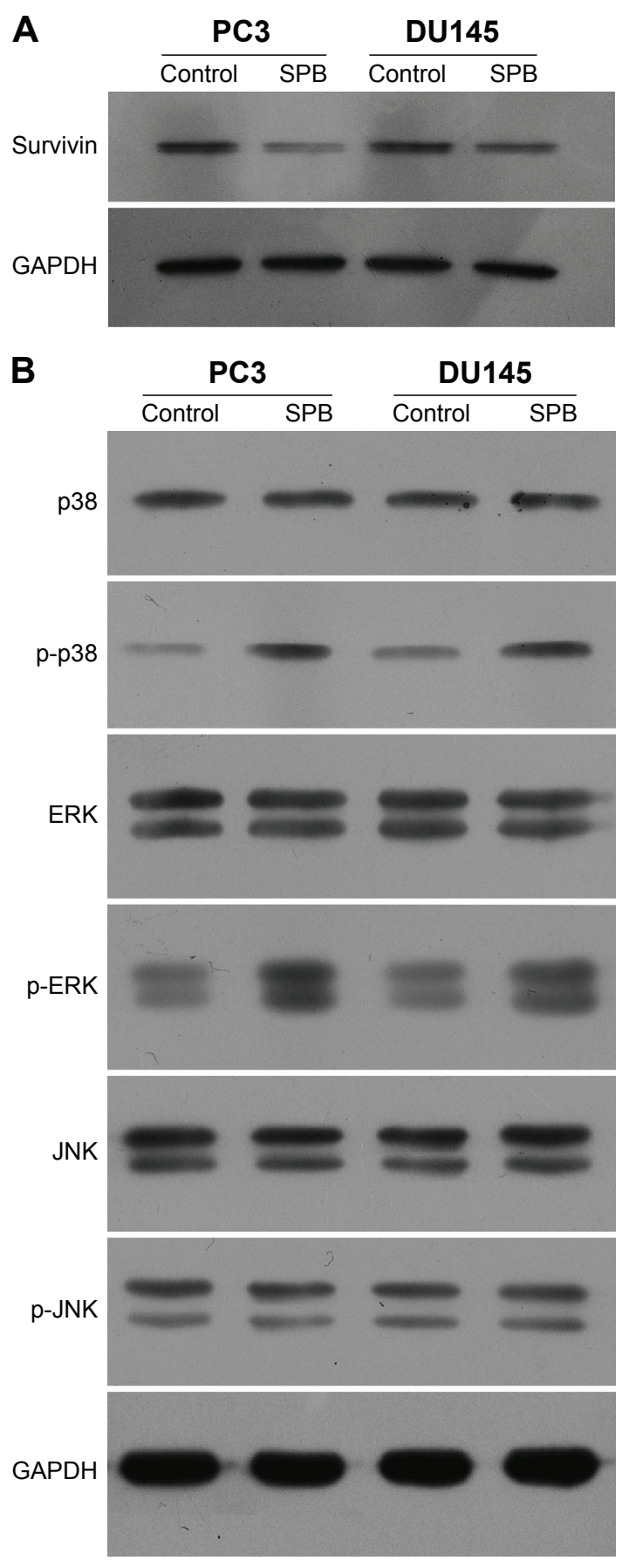

Figure 4 Representative images of Western blotting assay.

Notes: (A) SPB treatment remarkably inhibited the expression of survivin in both cell types. (B) SPB treatment increased the phosphorylation of p38 and ERK, while it had no effect on the activity of JNK.

Abbreviation: SPB, sodium phenylbutyrate.

\section{Treatment with SPB significantly inhibited tumor formation in vivo}

In vivo tumor formation models were induced by subcutaneous injection of $\mathrm{PCa}$ cells in SD rats. As illustrated in Figure 5, the volumes of tumors of PC 3 cells (Figure 5A) and DU145 cells (Figure 5B) were remarkably inhibited by SPB administration. In control groups, tumor sizes kept growing until the 28th day of the experiment, while in SPB groups the tumor sizes of 28th day stayed the same as those of first day of the experiment. And the differences between control groups and SPB groups were all statistically significant for the last three sampling time points $(P<0.01)$.

\section{Discussion}

Surgery and radiation therapies are currently the most effective treatment methods for patients with localized PCa. However, once metastasis occurs, these treatments become less effective. ${ }^{3,4}$ In this study, two human PCa cell lines, namely DU145 and PC3, were incubated with SPB to assess its potential as a treatment therapy for PCa. Given that SPB is involved in the regulation of the survivin pathway in other types of cancer, ${ }^{12}$ its influence on the expression pattern of survivin and MAPK members in PCa was also evaluated.

It is well established that SPB could affect many aspects of cellular function. As one of the histone deacetylase inhibitors, the major effect of SPB can be attributed to the regulation of the gene expression pattern caused by chromatin structure abnormality. In cancer treatment, SPB has been extensively investigated for its capability to trigger cell differentiation, G1 cell cycle arrest, and apoptosis. ${ }^{13}$ In the present study, we found that SPB inhibited the cell growth of both PCa cell lines; and SPB at $\mathrm{IC}_{50}$ also clearly led to the morphological demolition of PCa cells. Additionally, SPB increased the apoptotic rates in $\mathrm{PCa}$ cell lines dramatically over the basal rate by more than twice. These results evidently verified the conclusion of the previous study that SPB was capable of attenuating the viability of cancer cells. ${ }^{14}$ The effect of SPB on tumor cell migration and invasion ability was assessed, and a significant decrease in the number of cells migrating through the porous membrane was observed after the administration of SPB. In fact, the apoptosis and migration of $\mathrm{PCa}$ cells are closely associated with the transcription of survivin. ${ }^{11,15,16}$ By targeting the regulation of survivin, Zhang et $\mathrm{al}^{16}$ have shown that inhibition of the gene remarkably increases the sensitivity of PCa cancer cells to chemotherapeutic drugs. Furthermore, the expression change of survivin was synchronous with the effect of SPB on cell proliferation, colony formation, cell mobility, and cell apoptosis. As an important member of the apoptosis protein (IAP) family, survivin initiates the invasion of tumor cells by triggering the formation of a survivin-XIAP (X-linked inhibitor of apoptosis protein) complex. Additionally, the decreased expression of survivin would also facilitate the apoptosis in cancer cells. ${ }^{12,16}$ The connection between SPB 
A

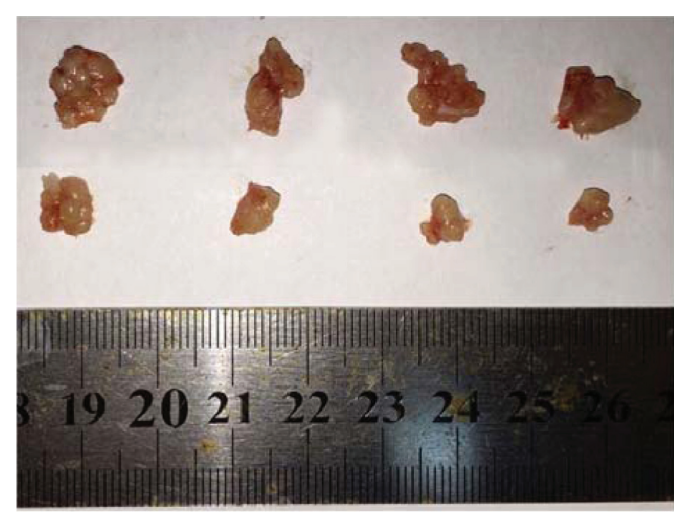

B

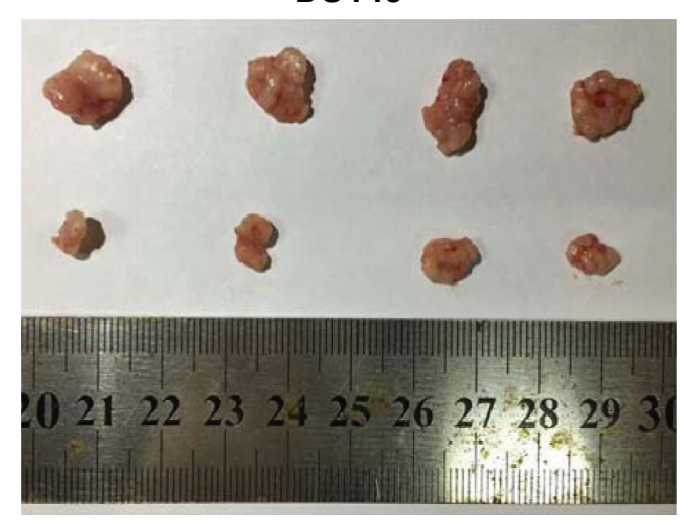

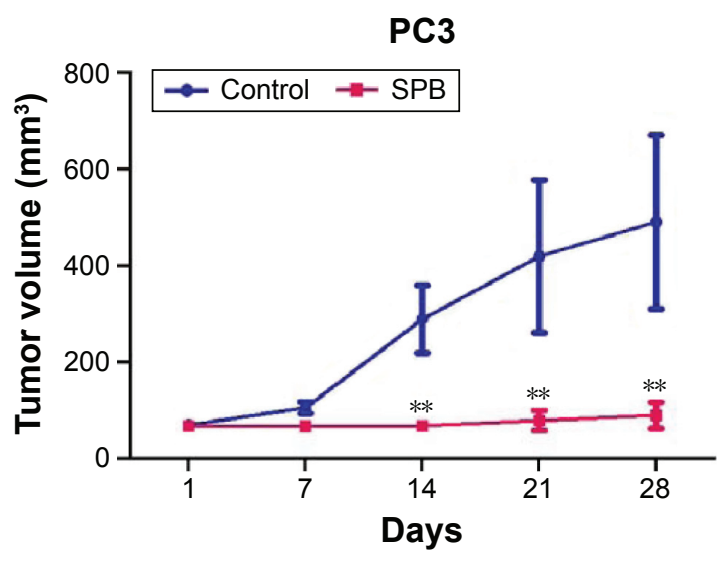

DU145

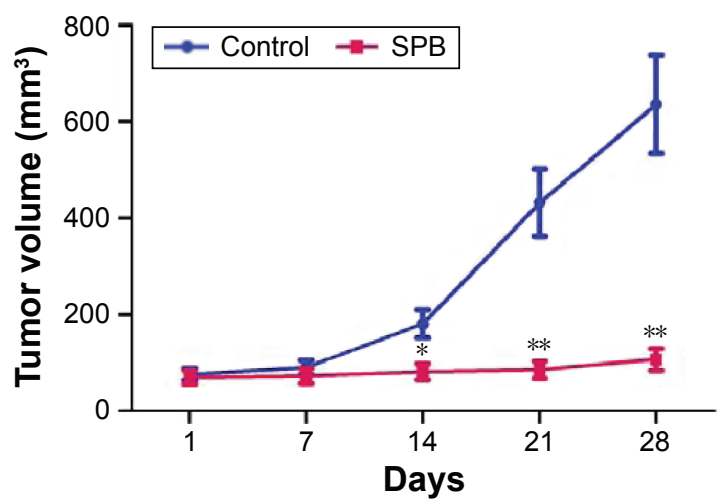

Figure 5 Representative images and quantitative analysis results of the effect of SPB treatment on tumor formation in vivo.

Notes: (A) Administration of SPB significantly inhibited the tumor formation of PC3 cells. (B) Administration of SPB significantly inhibited the tumor formation of DUI45 cells. "**” Means significantly different from the control group, $P<0.01$. "***” Means significantly different from the control group, $P<0.05$.

Abbreviation: SPB, sodium phenylbutyrate.

treatment and expression of survivin had also been previously validated with many types of cancers. ${ }^{12}$ Focusing on tongue squamous cancer, Chen et $\mathrm{al}^{12}$ found that SPB exhibited a remarkable inhibition effect on the cancer cell viability via the downregulation of survivin. Moreover, as reported by Chao et al, ${ }^{10}$ inhibition of survivin could serve as an inducer of cell death in bladder cancers in a p38 MAPK-dependent manner. These results were further verified with our data: inhibition of survivin by SPB treatment was associated with the upregulation of p-p38 and p-ERK, which might explain the effect of SPB in inducing apoptosis in PCa cells. Our work is the first to report on the interaction between SPB and survivin in PCa. Although preliminary and implicit, the findings in this study might offer another mechanism by which SPB antagonizes PCa, further confirming the potential of SPB in PCa treatment.

\section{Conclusion}

This study demonstrated that administration of SPB could be considered as a promising therapy against PCa. SPB not only inhibited the growth and migration of PCa cells but also induced the apoptosis of cancer cells. After the administration of SPB, the expression of survivin in DU145 and PC3 cell lines were both decreased, while the activation of pro-apoptosis indicators were strengthened, which might lower the risks of being attacked by metastasis in PCa patients. Although our results on the influence of SPB on the expression of survivin are superficial, it might highlight a possible pathway through which SPB antagonizes PCa. Still, the detailed mechanism underlying this process needs to be further explored in the future. Considering the possible cytotoxicity of high-dose SPB treatment, intermittent application of SPB combined with traditional chemotherapy agents may provide a more effective treatment for PCa.

\section{Acknowledgment}

This work was supported by the Science and Technology Planning Project of Guangdong Province, People's Republic of China (2013B022000066). 


\section{Disclosure}

The authors report no conflicts of interest in this work.

\section{References}

1. Howlader N, Noone AM, Krapcho M, et al. SEER Cancer Statistics Review, 1975-2008. Bethesda, MD: National Cancer Institute; 2011:19.

2. Zhu Y, Yang XQ, Han CT, et al. Pathological features of localized prostate cancer in China: a contemporary analysis of radical prostatectomy specimens. PLoS One. 2015;10(3): 0121076.

3. Bickers B, Aukim-Hastie C. New molecular biomarkers for the prognosis and management of prostate cancer - the post PSA era. Anticancer Res. 2009;29(8):3289-3298.

4. Siddiqui E, Mumtaz FH, Gelister J. Understanding prostate cancer. J R Soc Promot Health. 2004;124(5):219-221.

5. Huang L, Sowa Y, Sakai T, Pardee AB. Activation of the $\mathrm{p} 21^{\mathrm{WAF} / \mathrm{CIP} 1}$ promoter independent of $\mathrm{p} 53$ by the histone deacetylase inhibitor suberoylanilide hydroxamic acid (SAHA) through the Sp1 sites. Oncogene. 2000;19(50):5712-5719.

6. Kim Y-H, Park J-W, Lee J-Y, Kwon TK. Sodium butyrate sensitizes TRAIL-mediated apoptosis by induction of transcription from the DR5 gene promoter through $\mathrm{Sp} 1$ sites in colon cancer cells. Carcinogenesis. 2004;25(10):1813-1820.

7. Wang CT, Meng M, Zhang JC, et al. Growth inhibition and gene induction in human hepatocellular carcinoma cell exposed to sodium 4-phenylbutanoate. Chin Med J (Engl). 2008;121(17):1707-1711.

8. Lucci A, Hall CS, Lodhi AK, et al. Circulating tumour cells in nonmetastatic breast cancer: a prospective study. Lancet Oncol. 2012; 13(7):688-695.
9. Yie SM, Luo B, Ye NY, Xie K, Ye SR. Detection of survivin-expressing circulating cancer cells in the peripheral blood of breast cancer patients by a RT-PCR ELISA. Clin Exp Metastasis. 2006;23(5-6):279-289.

10. Chao JI, Su WC, Liu HF. Baicalein induces cancer cell death and proliferation retardation by the inhibition of $\mathrm{CDC} 2$ kinase and survivin associated with opposite role of $\mathrm{p} 38$ mitogen-activated protein kinase and AKT. Mol Cancer Ther. 2007;6(11):3039-3048.

11. Wang H, Yang M, Xu J, et al. Survivin mRNA-circulating tumor cells are associated with prostate cancer metastasis. Tumour Biol. Epub 2015 Aug 6.

12. Chen WQ, Feng FL, Gu HB, Pan DS. Effects of sodium phenylbutyrate on the apoptosis of human tongue squamous cancer cell line and expression of $\mathrm{p} 21$ and survivin gene. Chinese Journal of Stomatology. 2010;45(7):416-420.

13. Kusaczuk M, Bartoszewicz M, Cechowska-Pasko M. Phenylbutyric acid: simple structure - multiple effects. Curr Pharm Design. 2015;21(16): $147-2166$

14. Carducci MA, Nelson JB, Chan-Tack KM, et al. Phenylbutyrate induces apoptosis in human prostate cancer and is more potent than phenylacetate. Clin Cancer Res. 1996;2(2):379-387.

15. Rivadeneira DB, Caino MC, Seo JH, et al. Survivin promotes oxidative phosphorylation, subcellular mitochondrial repositioning, and tumor cell invasion. Sci Signal. 2015;8(389):ra80.

16. Zhang M, Mukherjee N, Bermudez RS, et al. Adenovirus-mediated inhibition of survivin expression sensitizes human prostate cancer cells to paclitaxel in vitro and in vivo. Prostate. 2005;64(3):293-302.
OncoTargets and Therapy

\section{Publish your work in this journal}

OncoTargets and Therapy is an international, peer-reviewed, open access journal focusing on the pathological basis of all cancers, potential targets for therapy and treatment protocols employed to improve the management of cancer patients. The journal also focuses on the impact of management programs and new therapeutic agents and protocols on

\section{Dovepress}

patient perspectives such as quality of life, adherence and satisfaction. The manuscript management system is completely online and includes a very quick and fair peer-review system, which is all easy to use. Visit http://www.dovepress.com/testimonials.php to read real quotes from published authors. 